\title{
On Polarographic Behaviour of Indium Ion in Potassium Thiocyanate
}

\author{
By \\ Takeo Takahashi and Hideko ShIRaI \\ Institute of Industrial Science, Univ. of Tokyo, Tokyo
}

(Received Dec. 5, 1962)

The d.c. polarographic reduction waves of indium and nickel ions in KSCN supporting electrolyte show minima." The phenomena have been little discussed in the literatures of d.c. polarography of these metallic ions. The present authors disclosed that the a.c. polarograms of $\mathrm{Ni}^{2+}, \mathrm{Cu}^{2+}$ and $\mathrm{In}^{3+}$ ions in $\mathrm{KSCN}$ solution, or $\mathrm{Co}^{2+}$ and $\mathrm{Ni}^{2+}$ ions in $\mathrm{NH}_{4} \mathrm{Cl}-\mathrm{NH}_{4} \mathrm{OH}$ solution showed the minium waves below the zero line of the recorder at very negative d.c. polarization. Among these ions, $\mathrm{In}^{3+}$ ion in $\mathrm{KSCN}$ solution distinctly shows the largest minimn wave, with which the present paper will deal. The d.c. and a.c. polarographs used in the present experiment were pen-writing, electronic selfbalancing type reJorders, ${ }^{2)}$ constructed in this laboratory. The rate of mercury flowing out of the capillary was $2.79 \mathrm{mg} / \mathrm{sec}$ and the reference electrode (NCE) was connected with the polarographic cell through an agar-agar bridge. The a.c. voltage of $10 \mathrm{mV}$ was applied in a.c. polarography, and the standard capacitance $\left(C_{s}\right)$ of $0.2 \mu \mathrm{F}$ and the standard resistance $\left(R_{s}\right)$ of $0.5 \mathrm{~K} \Omega$ were used in the present experiment.

\section{A.C. and D.C. Polarograms of Indium lon}

A.c. polarogram of $2 \mathrm{mM} \operatorname{In}\left(\mathrm{NO}_{3}\right)_{3}$ in $0.5 M \mathrm{KSCN}$ solution (pH 3) is given in Fig. 1-b.

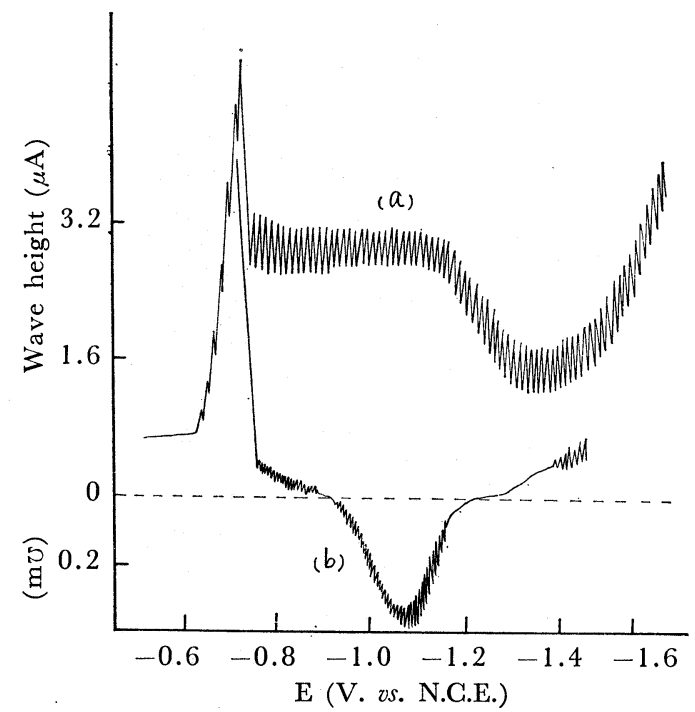

Fig. 1 D.c. and a.c. polarograms of $2 \mathrm{mM} \mathrm{In}^{3+}$ ion in $0.5 \mathrm{M} \mathrm{KSGN}$ solution $\left(25^{\circ} \mathrm{C}\right)$,
(a) d.c. polarogram,
(b) a.c. polarogram.

The polarogram runs below the zeroline and shows the minimum wave, whose minimum point is located near $-1.15 \mathrm{~V}$. The potential of minimum point approximately corresponds to the potential, at which the diffusion current in d.c. polarogram begins to decrease, as shown in Fig. 1-a. The minimum wave was also observed in $\mathrm{NH}_{4} \mathrm{SGN}$ supporting electrolyte solution likewise as in KSCN solution. The heights of minimum were almost the same if the concentrations of indium ion and thiocyanate ion are, respectively, the same in both electrolytes. Furthermore, it was found that those minimum waves have no relationship with an elapsed time after preparation of the electrolyte solution. The height of minimun was proportional 
to the concentration of indium ion, provided that the concentration of the supporting electrolyte was kept constant.

\section{Effect of $\mathrm{pH}$ upon the Minimum Wave}

The minimum wave in a.c. polarogram of $2 \mathrm{~m} M \mathrm{In}^{3+}$ ion in $0.5 M \mathrm{KSCN}$ solution did not depend upon the change of $\mathrm{pH}$, but it depended on $\mathrm{pH}$ in the presence of acetic acid. If $0.2 M$ acetic acid was added, the minimum wave disappeared in the d.c. polarogram of $2 \mathrm{mM}$ $\mathrm{In}^{3+}$ ion in $0.5 M \mathrm{NH}_{4} \mathrm{SCN}$ solution. ${ }^{3)} \quad$ Fig. 2 shows the d.c. polarograms of $2 \mathrm{mM} \mathrm{In}^{3+}$ ion in $1 M \mathrm{KSGN}$ at $\mathrm{pH} 2.55$ (b) and 4.1 (a). These polarograms give the maximum wave following the minimum wave. The magnitude of maximum wave tends to increase with increasing concentration of $\mathrm{H}^{+}$ion, so that the maximum wave may be assumed to be mainly the hydrogen wave. But the d.c. wave height of the supporting electrolyte at the same $\mathrm{H}^{+}$ion concentration without indium ion is not so large as the height of maximum wave stated above, so that the maximum wave can not be considered to be entirely due to the reduction of $\mathrm{H}^{+}$ion.

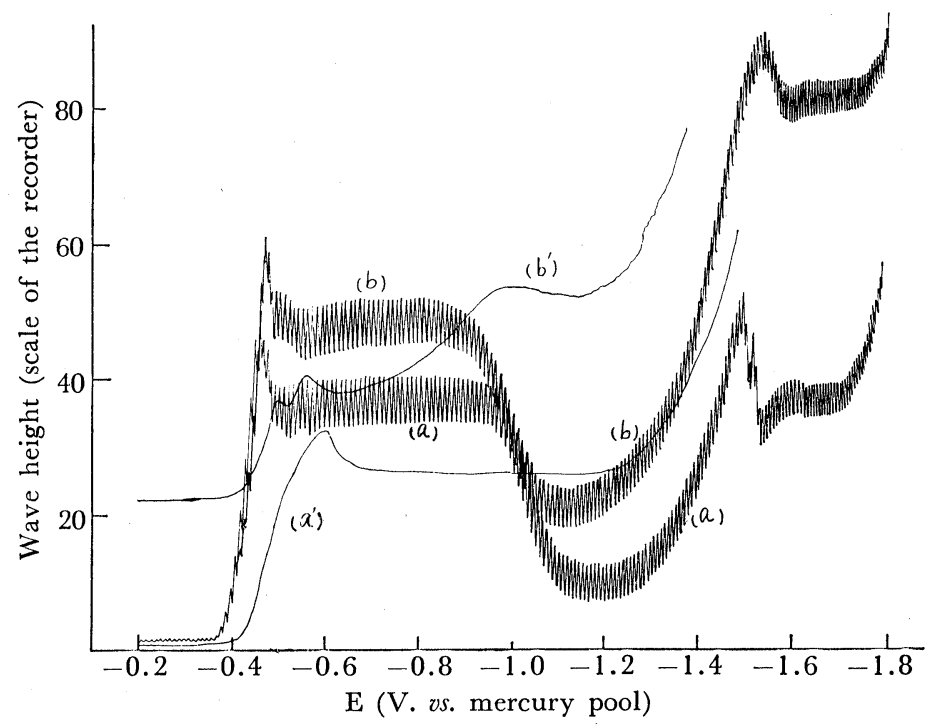

Fig. 2. D.c. polarograms of $2 \mathrm{~m} M \mathrm{In}^{3+}$ ion in $1 M \mathrm{KSCN}$ solution $\left(25^{\circ} \mathrm{C}\right)$,

(a) $\mathrm{pH} 4.1$, dropping mercury electrode, $12 \mu \mathrm{A}$ per 10 scale units,

(b) $\mathrm{pH} 2.55$, dropping mercury electrode, $12 \mu \mathrm{A}$ per 10 scale units,

$\left(\mathrm{a}^{\prime}\right) \mathrm{pH} 4.1$, stationary platinum electrode, $4 \mu \mathrm{A}$ per 10 scale units,

(b') $\mathrm{pH} 2.55$, statinary platinumelectrode $8 \mu \mathrm{A}$ per 10 scale units.

\section{Composition of Indium Complex Participating in the Electrode Reaction}

Analysis of $\log \left(i / i_{d}-i\right)$ vs. $E$ curve of d.c. polarogram of $\operatorname{In}^{3+}$ ion in KSGN solution indicates that the electrode reaction of $\mathrm{In}^{3+}$ ion is a reversible reaction with three electron transfer. The effects of the concentration $(1 \sim 0.4 M)$ of $\mathrm{KSCN}$ and of $\mathrm{H}^{+}$ion $(\mathrm{pH} 3 \sim 5)$ upon the shift of the summit potential in a.c. polarogram of $\mathrm{In}^{3+}$ ion confirmed the following composition of Indium complex participating in the electrode reaction. The shift was $40 \mathrm{mV}$ per unit change of the logarithm of KSCN concentration, indicating the liberation of two $\mathrm{SCN}^{-}$ions from the electrode surface, provided that the reduction follows the Heyrovský-Ilkovič formula. Furthermore, the shift was found to be little against the change of $\mathrm{pH}$, showing the indifference of the electrode reaction toward $\mathrm{OH}^{-}$ion. It can be concluded that the indium complex such as $\operatorname{In}(\mathrm{SCN})_{2}{ }^{+}$ion participates in the electrode reaction. 


\section{Effect of the Addition of Gelatine}

Fig. 3 shows that the minimum wave of $2 \mathrm{mM} \mathrm{In}^{3+}$ ion in $1 M$ KSGN solution disappears by addition of gelatine to $0.003 \%$ at $\mathrm{pH} 4.6$. The more amount of gelatine had to be added to eliminate the minimum wave when the solution became more acidic. The disappearance of the minimum wave was also accompanied with the disappearance of the maximum wave.

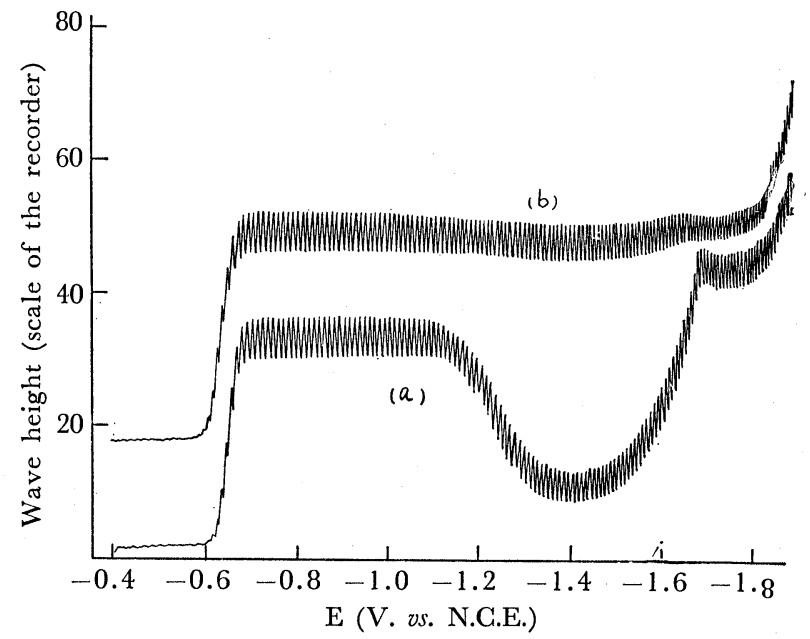

Fig. 3. Effect of the addition of gelatine upon minimum wave of $2 \mathrm{mM} \mathrm{In}^{3+}$ ion in $1 M \mathrm{KSCN}$ solution ( $\mathrm{pH} 4.6,25^{\circ} \mathrm{C}$ ),

(a) d.c. polarogram in the absence of gelatine,

(b) d.c. polarogram in the presence of $0.003 \%$ gelatine, $4 \mu \mathrm{A}$ per 10 scale units.

\section{Effect of Addition of the Hydrogen Peroxide.}

The minimum wave of indium ion in $1 M \mathrm{KSCN}$ solution of $\mathrm{pH} 4.5$ disappeared, as shown in Fig. 4, by adding hydrogen peroxide to about $0.01 \%$. The reduction wave of

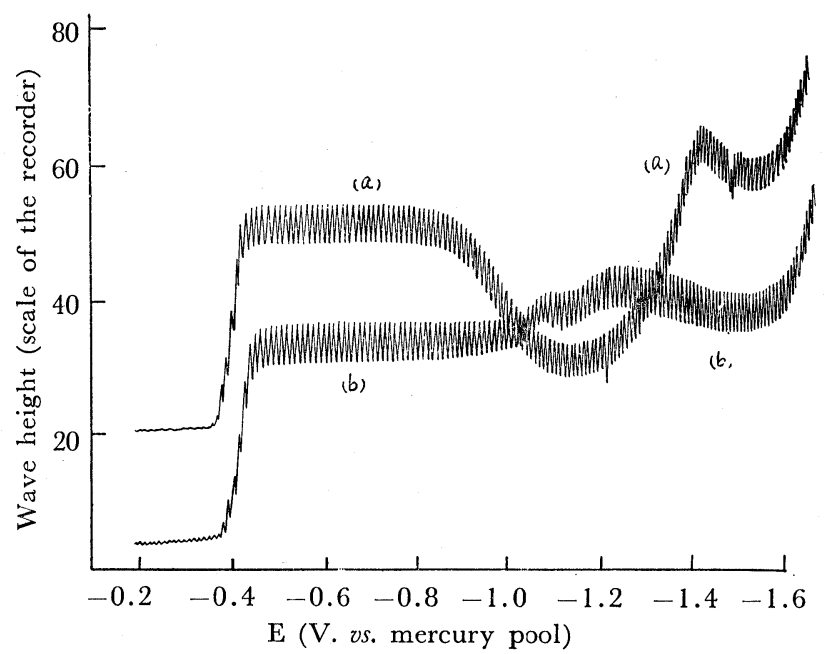

Fig. 4. Effect of hydrogen peroxide on minimum wave of $2 \mathrm{mM} \mathrm{In}^{3+}$ ion in $1 M \mathrm{KSGN}$ solution $\left(\mathrm{pH} 4.6,25^{\circ} \mathrm{C}\right), 4 \mu \mathrm{A}$ per 10 scale units,

(a) d.c. polarogram in the absence of $\mathrm{H}_{2} \mathrm{O}_{2}$,

(b) d.c. polarogram in the presence of $0.01 \% \mathrm{H}_{2} \mathrm{O}_{2}$. 
hydrogen peroxide should be observed at the same potential region as that of the minimum wave. However, the concentration level of hydrogen peroxide at this experiment is too low to attribute the result to the cancellation of the minimum current by the reducion current of hydrogen peroxide. Therefore the disappearance of the minimum wave in the presence of $\mathrm{H}_{2} \mathrm{O}_{2}$ is likely due to the increase of $\mathrm{pH}$ caused by the formation of $\mathrm{OH}^{-}$ion in the electrode reduction of hydrogen peroxide.

\section{Current-Voltage Curve with Stationary Platinum Electrode.}

In Fig. 2 are also shown the current-voltage curves of indium ion in KSCN solution, obtained with a statitionary platinum wire electrode ( $4 \mathrm{~mm}$ in length, $0.5 \mathrm{~mm}$ in diameter). In both curves $\left(\mathrm{a}^{\prime}\right)$ and $\left(\mathrm{b}^{\prime}\right)$, observed at $\mathrm{pH} 4.1$ and 2.55, respectively, no minima are observed, while the minimum waves appear with the dropping mercury electrode (curves (a) and (b)) at the same conditions. The curve- $b$ ' is a double wave, of which the second wave was identified to be a hydrogen wave by the appearance of gaseous bubbles on the platinum electrode.

\section{Effect of Other Factors upon A.C. Minimum Wave.}

The depth of the a.c. minimum wave (referred to the base line) was influenced by the magnitude of the superimposed a.c. voltage. Table 1 shows that the depth of the minimum wave decreases with the increase of the a.c. voltage from $5 \mathrm{mV}$ to $50 \mathrm{mV}$. On the contrary, the depth increased with the elevation of temperature as shown in Table 2.

Table 1 Effect of the Applied A.C. Voltage on the Minimum Wave

\begin{tabular}{l|c|c|c|c}
\hline Applied a.c. volt. & 5 & 10 & 30 & 50 \\
\hline Depth of miuimum wave (cm) & 5.4 & 4.95 & 4.14 & 3.37 \\
\hline
\end{tabular}

Table 2 Effect of the Temperature on the Minimum Wave

\begin{tabular}{l|c|c|c|c|c|c|c}
\hline Temp. $\left({ }^{\circ} \mathrm{C}\right)$ & 14.5 & 15.5 & 18 & 24 & 29 & 31.5 \\
\hline Depth of minimum wave (cm) & 3.15 & 3.51 & 3.51 & 4.23 & 4.32 & 4.54 \\
\hline
\end{tabular}

Insertion of a resistance in series in the circuit lowered the a.c. wave ("normal" or "positive" current referred to the base line) of indium ion, while the depth of minimum wave increased with the increase of the outer resistance as shown in Fig. 5. Such an effect of the outer resistance as confirmed in indium wave was not observed in case of the reduc-

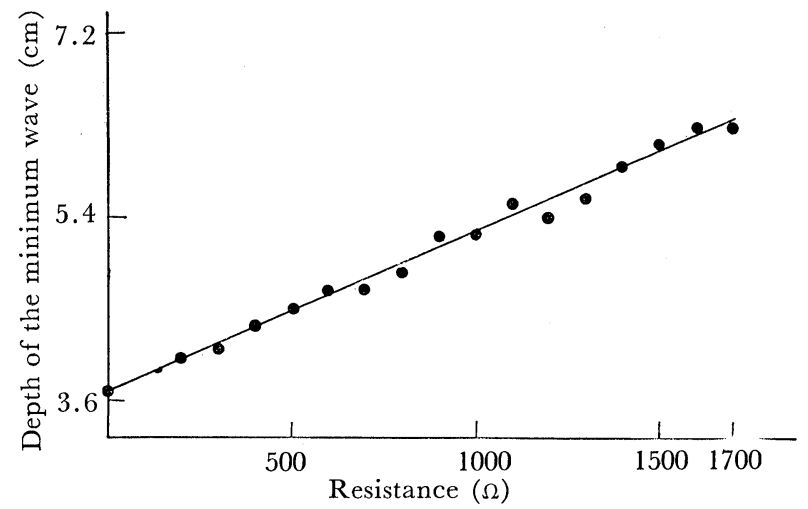

Fig. 5. Effect of outer resistance upon the depth of minimum

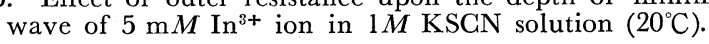




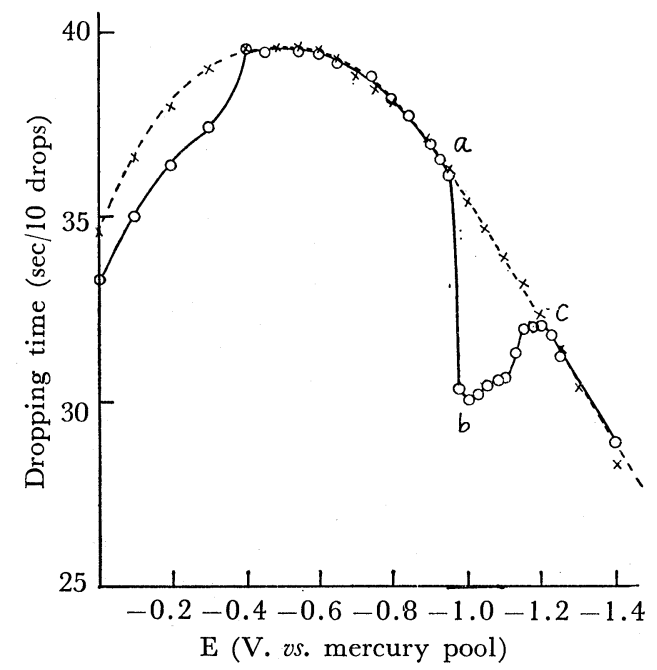

Fig. 6. The electrocapillary curve in $1 M \mathrm{KSGN}$ solution with and without $5 \mathrm{~m} M \mathrm{In}^{3+}$ ion $\left(\mathrm{pH} 3.6,25^{\circ} \mathrm{C}\right)$.

$--\times--1 M \mathrm{KSGN}$

$-\mathrm{O}-1 M \mathrm{KSCN}$ in the presence of $5 \mathrm{~m} M \operatorname{In}\left(\mathrm{NO}_{3}\right)_{3}$ tion wave of $\mathrm{Cd}^{2+}$ ion in $\mathrm{KSCN}$, where only the decrease of the height of normal a.c. wave was observed.

\section{Electrocapillary Curve}

Fig. 6 shows the electrocapillary curves of $1 M \mathrm{KSCN}$ solutions with and whithout indium ion. In the presence of indium ion the electrocapillary curve begins to deviate from that of $1 M$ KSCN solution without indium ion at the potential of $c a$. $-0.95 \mathrm{~V}$. vs. Hg-pool. This potential corresponds to the potential from which the initial decrease of the diffusion current begins on the d.c. polarogram of indium ion. Namely, the interfacial tension as expressed by the dropping time (sec) per 10 drops of mercurry decreases markedly from (a) to (b) and then gradually increases to (c), approaching to the electrocapillary

curve obtained in the absence of indium ion. The potential at (c) corresponds to the minimum point of the abnormal diffusion current.

The same abnormality of electrocapillary curve is seen in a.c. polarography; the curve begins to deviate near the minimum point of the a.c. minimum wave and return to the normal electrocapillary curve of supporting electrolyte at the potential, at which the a.c. minmum wave comes to the end.

\section{Considerations}

In conclusion the minimum wave and the following maximum wave observed on the d.c. polarograms of indium ion in KSCN supporting electrolyte solution will be briefly discussed. From the stated experimental results it is sure that the maximum wave is intimately related to a hydrogen wave. The minimum wave disapears by addition of hydrogen peroxide. Although gelatine is effective to eliminate the minimum wave, the more amount of gelatine is needed when the solution is more acidic. These experimental results indicate that the high concentration of hydrogen ion facilitates the apperance of the minimum wave. Furthermore, the abnormal behaviour of the electrocapillary curve is observed in the presence of indium at the d.c. potential, where the minimum wave appears. This fact makes us to suppose that the minimum wave is connected with the adsorption phenomenon on the electrode surface.

\section{Reference}

1) M. Ishibashi, T. Fujinaga : "Polarographic Analysis" (Japanease) (1956) 36. Maruzen Publ. Co.

2) T. Takahashi, E. Niki : Talanta, 1, (1959) 245.

E. Niki : Study on Polarography, Jap. 1, No. 4, 27 ; (1954) 3, No. 2, 41 (1956).

3) H. Shirai, J. Chem. Soc. Japan, Pure Chem. Sect., 81, 1248 (1960). 